\title{
ECONOMICAL ANALYSIS OF PROJECT MANAGEMENT UNDER CONSIDERATION OF MULTI-CRITERIA DECISIONS
}

\author{
Guest Editor \\ Friedel Peldschus \\ Leipzig University of Applied Sciences (Germany) \\ E-mail:peldschu@fbb.htwk-leipzig.de
}

An international colloquium on this topic took place in Leipzig (Germany) on May 19-21, 2005. This colloquium is organised bi-annually by VGTU Vilnius, TU Poznan and the host of this $10^{\text {th }}$ colloquium, HTWK Leipzig.

Since the beginning at Leipzig Technical University in 1986 the number of attendants has continuously grown, so that today participants come from 8 different countries. The idea of exchanging views on construction management at an international level led to the collaboration on research works as well as the publication of scientific books. The exchange of $\mathrm{PhD}$ candidates and joint examination procedures for doctorates and state doctorates are characteristic for these co-operations.

Multi-criteria decisions are of particular importance in the era of globalisation, because the complexity of technical problems and their influencing factors are reaching dimensions that can no longer be solved by traditional engineering knowledge alone. In addition, more and more integration of technical and economical problems is observed. Therefore the solution of such problems can only result from a successful collaboration of several institutions. The regularly held colloquia serve the mutual exchange on recent findings on the solution of these problems.

The $10^{\text {th }}$ colloquium shows a wide range of topics. A lot of issues were discussed besides the main scope of exchange about solutions for multi-criteria decisions and decisionaiding systems. These include problems of facility management, construction economics, construction operation and the improvement of student education. 31 presentations were given in total. They were grouped thematically into different sections.

In the section of "Construction Economics and Rationalisation" presentations were given on cost analysis of high speed routes of railway transport in Europe, project structure and cost effectiveness of hospital construction, integral assessment of the profitability of construction enterprises' activities, cost estimate aspects of investment construction projects, transition to flexible working hours a step towards a humane working environment. Besides presentations on economical investigations for specific construction projects a particular focus was on the discussion about the transition to flexible working hours and on the prognosis of the future labour demand. This topic is of particular interest in an era of high unemployment rates.

The section of "New Educational Methods" comprised presentations on the business game 'BAUMARKT' experiences with a new educational method; e - learning and group-oriented e - training, recent experiences; construction knowledge systems in Vilnius Gediminas Technical University; modelling construction processes: the retrospection and the anticipated research at the Poznan University of Technology. The section focused on the IToriented education. By exchanging experiences the effectiveness of the new methods could be compared.

In the section "Multi-Criteria Decisions in Civil Engineering" the participants presented their findings on refurbishment decision support system; construction project cash flow in aspect of model IVO; some aspects of working capital management in a building company; hybrid system for technological decision-aid in construction industry; group decision making with multiple objectives, the possibilities of verbal decision analysis methods for construction solutions; proposition of defining preferences of decision process participants, represented by groups of representatives; real estate knowledge management systems, sensitivity analysis of real estate valuation under conditions of uncertainty. The participants of the colloquia have been working on these topics for many years and they have proven numerous applications. Thus the actual scope of the 
colloquium is represented by this section. New applications of multi-criteria decision to real-estate management have to be pointed out here.

The section "Facility Management" included presentations on knowledge-intensive services in facility management; facility management aspects of maintenance strategies for buildings and building services systems; managing maintenance of housing stock: principles, tools and professionalism, new cooperation trends in the building industry. These problems, being up to date in all European countries, were discussed in a European as well as a buildingspecific perspective. The participants could observe the different views between the represented countries.

In the section "Construction Process" presentations were given on cost effectiveness analysis of the application of concrete; applications of multifactor model LITCAC in organisation of assembly works of flexible corrugated steel structure; simulation of the chosen processes of concrete works; construction and maintenance of roads based on PPP/PFI systems in polish environment; early age shrinkage of concrete modified by the chemical admixtures. The discussion in this section concentrated on the analysis of practical problems of the construction operation under economical aspects.

The following conclusions of the $10^{\text {th }}$ colloquium can be given:

- A successful co-operation of 20 years can be observed.

- The co-operation has supported the successful qualification of young scientists.

- The range of functions of construction management requires an extension of the co-operation integrating further scientific institutions in the framework of the European Union.

- The formation of a "European Working Group of Research in Construction Management" by the participants of the colloquium coming from eight different countries is proposed.

The presentations were published in English and German. The following special edition was printed as conference-accompanying information: Podium, Hochschule für Technik, Wirtschaft und Kultur, "10. Internationales Kolloquium Planungsinstrumente für das Projektmanagement", Sonderheft 2005, 11th volume, ISSN 14383926,68 pages. Due to the amount and comprehensiveness of presentations not all of them could be printed in that special edition. Therefore special thanks go to VGTU Vilnius for the possibility of publishing the remaining contributions in this journal. 